\title{
Estimating the Absolute Salinity of Chinese offshore waters using nutrients and inorganic carbon data
}

\author{
Fengying $\mathrm{Ji}^{1}$, Rich Pawlowicz ${ }^{2}$, and Xuejun Xiong ${ }^{3}$ \\ ${ }^{1}$ National Marine data and information service, Tianjin, 300171, China \\ ${ }^{2}$ Department of Earth, Ocean, and Atmospheric Sciences, University of British Columbia, Vancouver, BC V6T 1Z4, Canada \\ ${ }^{3}$ First Institute of Oceanography, Ministry of Natural Resources, Qingdao, 266001, China
}

Correspondence: Xuejun Xiong (xiongxj@fio.org.cn)

Received: 7 February 2021 - Discussion started: 18 February 2021

Revised: 18 April 2021 - Accepted: 28 April 2021 - Published: 9 July 2021

\begin{abstract}
In June 2009, the Intergovernmental Oceanographic Commission of UNESCO released The international thermodynamic equation of seawater - 2010 (TEOS-10 for short; IOC et al., 2010) to define, describe and calculate the thermodynamic properties of seawater. Compared to the Equation of State-1980 (EOS-80 for short), the most obvious change with TEOS-10 is the use of Absolute Salinity as salinity argument, replacing the Practical Salinity used in the oceanographic community for 30 years. Due to the lack of observational data, the applicability of the potentially increased accuracy in Absolute Salinity algorithms for coastal and semi-enclosed seas is not very clear to date. Here, we discuss the magnitude, distribution characteristics, and formation mechanism of Absolute Salinity and Absolute Salinity Anomaly in Chinese shelf waters, based on the Marine Integrated Investigation and Evaluation Project of the China Sea and other relevant data. The Absolute Salinity $S_{\mathrm{A}}$ ranges from 0.1 to $34.66 \mathrm{~g} \mathrm{~kg}^{-1}$. Instead of silicate, the main composition anomaly in the open sea, $\mathrm{CaCO}_{3}$ originating from terrestrial input and re-dissolution of shelf sediment is most likely the main composition anomaly relative to SSW and the primary contributor to the Absolute Salinity Anomaly $\delta S_{\mathrm{A}}$. Finally, relevant suggestions are proposed for the accurate measurement and expression of Absolute Salinity of the China offshore waters.
\end{abstract}

\section{Introduction}

Absolute Salinity, which is traditionally defined as the mass fraction of dissolved material in seawater, replaces Practical Salinity as the salinity argument in the TEOS-10 (IOC et al., 2010) seawater standard for the thermodynamic properties of seawater. This is because these thermodynamic properties are directly influenced by the mass of dissolved constituents, whereas Practical Salinity depends only on their conductivity. Since the relative amounts of different constituents change from place to place and from time to time, accounting for the biases that are introduced by these changes may be important. However, appropriate methods for frequent and regular measurements of the dissolved content directly in ocean studies are still a topic of research.

At present, the TEOS-10 Absolute Salinity of a seawater sample is obtained by adding the Absolute Salinity Anomaly $\delta S_{\mathrm{A}}$ to Reference Salinity $S_{\mathrm{R}}$, in which $S_{\mathrm{R}}$ is the mass fraction of dissolved material in a stoichiometric composition model (the Reference Composition or RC) of seawater, defined by Millero (2008), for which the reference material known as International Association for the Physical Sciences of the Ocean (IAPSO) Standard Seawater (SSW for short), is a good approximation and of the same conductivity as that of the sample. $\delta S_{\mathrm{A}}$ is the mass fraction change caused by composition variations relative to $\mathrm{RC}$. Three algorithms for calculating Absolute Salinity in the open ocean are provided in TEOS-10. The two that avoid a direct measurement either make assumptions about the dominant biogeochemical processes in the ocean that affect the Absolute Salinity Anomaly or rely on empirically determined correlations. 
However, the applicability and accuracy of the TEOS10 algorithms are still not very clear for estuaries and semi-enclosed oceanic basins where the relative compositions of the seawater may be different from that of the open ocean. Although there have only been very few direct measurements of conductivity and density in such areas (Millero, 1984; Feistel et al., 2010a), Pawlowicz (2015) used chemical-composition-conductivity-density modeling and climatological data to estimate the Absolute Salinity Anomaly near many rivers around the world, finding values of up to 1 order of magnitude higher than those extrapolated from the open ocean.

The coastal areas of China comprise one of the widest shallow seas in the world, with a large north-south span, numerous estuaries and bays, and a large amount of freshwater input from rivers. The relative composition of this coastal seawater may not only differ from that of the open ocean but also vary from place to place. However, the influence of relative composition variation on the Absolute Salinity in this area has never been systematically studied, although salinity measurement has played an important role in Chinese national ocean survey projects since 1957 (CSTPRC, 1964) and for metrological purposes a Chinese primary seawater standard has been developed ( $\mathrm{Li}$ et al., 2016). Moreover, in any efforts to detect salinity variations associated with climate change variability in the Bohai and northern Yellow seas (Wu et al., 2004a, b; Xu, 2007; Lv, 2008; Song, 2009), Practical Salinity $S_{\mathrm{P}}$ is still used as the simplicity of Absolute Salinity, and its change caused by the relative composition variation is ignored. That will raise obvious problems in the correct presentation of time series and/or transects that begin near the coast and end well offshore (Wright et al., 2011).

Therefore, in this paper we first clarify the definition, status, and application of TEOS-10 Absolute Salinity. Second, based on the measured data and related research results, we estimate the magnitude, temporal and spatial distribution characteristics, and formation mechanisms giving rise to $\mathrm{Ab}-$ solute Salinity Anomalies in Chinese coastal seawaters. Finally, based on the above results, we put forward relevant suggestions and future research directions for the accurate measurement and expression of Absolute Salinity of Chinese offshore seawaters.

\section{Methods and data}

\subsection{Calculation of Absolute Salinity}

The TEOS-10 Solution Absolute Salinity of seawater is essentially based on adding up the mass of solute in a seawater sample:

$S_{\mathrm{A}}^{\mathrm{soln}}=\sum_{i=1}^{N_{\mathrm{c}}} M_{i} c_{i}$, where $c_{i}$ is the molar concentration of component $i$ in seawater kg ${ }^{-1}, M_{i}$ is the molar mass of the component, and $N_{\mathrm{c}}$ is the number of species of component in seawater. However, it is impractical to carry out a full chemical analysis for the seawater to get the $S_{\mathrm{A}}^{\text {soln }}$ regularly. The primary and most demanding purpose of oceanographic salinity measurements is the calculation of seawater density to estimate significant ocean currents driven by sometimes tiny horizontal pressure gradients. In TEOS-10, Absolute Salinity is instead defined so that the density of seawater can be accurately calculated by the following equation:

$\rho=f_{\text {TEOS-10 }}\left(S_{\mathrm{A}}, t, p\right)$,

where $f_{\text {TEOS-10 }}$ is a specified function. Therefore, $S_{\mathrm{A}}$ is also called a Density Salinity.

Unfortunately, although for many purposes we can treat $S_{\mathrm{A}}$ and $S_{\mathrm{A}}^{\text {soln }}$ interchangeably, at highest precisions $S_{\mathrm{A}} \neq$ $S_{\mathrm{A}}^{\text {soln }}$ due to small changes in the relative composition of sea salt. In order to get $S_{\mathrm{A}}$ at this highest precision, Millero (2008) first defines a stoichiometric composition model (the Reference Composition or RC), based on a reference material (IAPSO Standard Seawater), and specifies an algorithm to determine a consistent estimate of the mass fraction of dissolved material in a sample of arbitrary salinity with the RC. This estimate is based on the widely used Practical Salinity $S_{\mathrm{P}}$ (UNESCO, 1981):

$S_{\mathrm{R}}=u_{\mathrm{PS}} \cdot S_{\mathrm{P}}, \quad 2<S_{\mathrm{P}}<42$.

In Eq. (3), the factor $u_{\mathrm{PS}}$ between the Reference Salinity of Standard Seawater and the Practical Salinity is $(35.16504 / 35) \mathrm{g} \mathrm{kg}^{-1}$ and is not equal to 1 mainly because an evaporative technique used by Sørensen in 1900 (Forch et al., 1902) led to the loss of some volatile components of dissolved material.

General seawater can be regarded as the mixture of Standard Seawater concentrated/diluted with pure water and a small amount of other components. The calculation formula of Absolute Salinity from Reference Salinity requires the addition of a correction, the Absolute Salinity Anomaly $\delta S_{\mathrm{A}}$ :

$S_{\mathrm{A}}=S_{\mathrm{R}}+\delta S_{\mathrm{A}}$.

At present there are three methods for determining the Absolute Salinity Anomaly $\delta S_{\mathrm{A}}$. First, it can be obtained by comparisons with direct density measurements performed in the laboratory (Millero et al., 2008; Wright et al., 2011). According to the density difference $\rho=\rho^{\text {lab }}-\rho\left(S_{\mathrm{R}}, 25^{\circ} \mathrm{C}, 0 \mathrm{dbar}\right)$ and the haline contraction coefficient, which is 0.7519 for $\mathrm{SSW}, \delta S_{\mathrm{A}}$ is determined by

$$
\left.\frac{\partial \rho}{\partial S_{\mathrm{A}}}\right|_{t=25^{\circ} \mathrm{C}, p=0 \mathrm{dbar}} \approx 0.7519 \mathrm{~kg} \mathrm{~m}^{-3}\left(\mathrm{~g} \mathrm{~kg}^{-1}\right)^{-1} \text {. }
$$

This procedure is useful for laboratory studies or in situations where ocean water can be obtained from sampling bottles retrieved from certain depths for subsequent laboratory measurements of density. 
Second, it can be estimated using a correlation equation whether chemical measurements of the most variable seawater constituents in the open ocean (carbonate system and macro-nutrients) are also available (Pawlowicz et al., 2011; IOC et al., 2010).

$$
\begin{aligned}
& \delta S_{\mathrm{A}}^{\text {dens }} /\left(\mathrm{mg} \mathrm{kg}^{-1}\right)=55.6 \times \Delta[\mathrm{NTA}]+4.7 \\
& \times \Delta[\mathrm{NDIC}]+38.9 \times\left[\mathrm{NO}_{3}^{-}\right]+50.7 \times\left[\mathrm{S}_{i}(\mathrm{OH})_{4}\right]
\end{aligned}
$$

The units of each component on the right are all millimole per kilogram, $\Delta[\mathrm{NTA}]=\mathrm{TA}-2.3 \times S_{\mathrm{P}} / 35$ is the standardized change in Total Alkalinity (TA), and $\Delta[\mathrm{NDIC}]=\mathrm{DIC}-$ $2.08 \times S_{\mathrm{P}} / 35$ is the standardized change in total Dissolved Inorganic Carbon (DIC). Note that the coefficients of this model are calculated using a numerical model for chemical interactions (Pawlowicz, 2008, 2010; Pawlowicz et al., 2011), which performed well against lab studies and were shown to have reasonable accuracy for seawater samples by Wooseley et al. (2014). An important aspect of this modeling is that, in order to maintain a charge balance in the dissolved constituents, it was assumed that calcium concentrations also changed according to

$\Delta[\mathrm{NTA}]=2 \Delta \mathrm{N}\left[\mathrm{Ca}^{2+}\right]-\Delta\left[\mathrm{NO}_{3}^{-}\right]$,

in which $\Delta \mathrm{N}\left[\mathrm{Ca}^{2+}\right]=\mathrm{Ca}^{2+}-10656.6 \cdot S_{\mathrm{P}} / 35 /\left(\mu \mathrm{mol} \mathrm{kg}{ }^{-1}\right)$ and $\mathrm{Ca}^{2+}$ and $S_{\mathrm{P}}$ are the measured value of $\mathrm{Ca}^{2+}$ and Practical Salinity of seawater, respectively. Calcium was chosen to balance charge since it is (a) not usually measured but (b) it is known to vary in its relative composition by a few percent in the open ocean. However, the accuracy of this relationship is not known.

Third, Absolute Salinity Anomaly $\delta S_{\mathrm{A}}$ can be found from a global $\delta S_{\mathrm{A}}$ climatology created by McDougall et al. (2012). Due to the lack of seawater component data, McDougall et al. (2012) carried out regression calculation on the Practical Salinity, density, and silicate concentration data of 811 seawater samples worldwide and found that $\delta S_{\mathrm{A}}$ can be directly related to $\mathrm{S}_{i}(\mathrm{OH})_{4}$ :

$$
\begin{gathered}
\delta S_{\mathrm{A}} /\left(\mathrm{g} \mathrm{kg}^{-1}\right)=\left(S_{\mathrm{A}}-S_{\mathrm{R}}\right) /\left(\mathrm{g} \mathrm{kg}^{-1}\right) \\
=98.24\left(\mathrm{~S}_{i}(\mathrm{OH})_{4} /\left(\mathrm{mol} \mathrm{kg}^{-1}\right)\right),
\end{gathered}
$$

although for further work the numerical coefficient was tuned for specific ocean basins. Taking the effects of evaporation and rainfall on ocean salinity into consideration, Eq. (8) can be simplified as

$\delta S_{\mathrm{A}}=R^{\delta} S_{\mathrm{R}} \quad$ (except the Baltic Sea),

in which $R^{\delta}=\delta S_{\mathrm{A}}^{\text {atlas }} / S_{\mathrm{R}}^{\text {atlas}}$; both the $S_{\mathrm{R}}^{\text {atlas }}$ and $\delta S_{\mathrm{A}}^{\text {atlas }}$ are from the Gouretski and Koltermann (2004) hydrographic atlas.

$S_{\mathrm{A}}=u_{\mathrm{PS}} S_{\mathrm{P}}\left(1+R^{\delta}\right)=\frac{35.16504 /\left(\mathrm{g} \mathrm{kg}^{-1}\right)}{35} S_{\mathrm{P}}\left(1+R^{\delta}\right)$
Equation (10) is adopted in the official Gibbs SeaWater Oceanographic Toolbox (available from http://www.teos-10. org, last access: 8 June 2021, McDougall and Barker, 2011) to calculate that $\delta S_{\mathrm{A}}$ with uncertainty in the ocean is less than $0.0047 \mathrm{~g} \mathrm{~kg}^{-1}$. For the semi-enclosed Baltic Sea, Feistel et al. (2010a) have fitted an empirical formula for calculating $\delta S_{\mathrm{A}}$, which is mainly due to rivers bringing material of anomalous composition into the Baltic Sea, and this formula has also been incorporated into the Gibbs SeaWater (GSW for short) algorithm library.

In the work described here we compare the latter two methods.

\subsection{Observation data}

The near-synchronous oceanographic and ocean chemical data used here are from 1480 stations covering Chinese offshore waters that were set up for the Marine Integrated Investigation and Evaluation Project of the China Sea conducted by the State Oceanic Administration of China (Xiong, 2012; Ji, 2016), as shown in Fig. 1. At these sites, surface, $10 \mathrm{~m}, 30 \mathrm{~m}$ and bottom values for nutrients, as well as $\mathrm{TA}$ and $\mathrm{pH}$, are available for the four seasons of spring (April-June), summer (July-September), autumn (OctoberDecember), and winter (January-March) of 2006 to 2007. Since in situ observation of DIC is missing in this project, it is derived from $\mathrm{pH}$ and TA data using the CO2SYS software released by the Department of Ecology of Washington State, USA, based on the carbonate equilibrium (Lewis and Wallace, 1998).

\section{Results}

\subsection{Reference Salinity $S_{\mathrm{R}}$ of the China offshore seawater}

The first step in determining Absolute Salinity is to estimate the Reference Salinity based on the Practical Salinity. Because the standard PSS-78 algorithm for Practical Salinity is only valid in the range $2<S_{\mathrm{P}}<42$, values for samples in the mouth of the Yangtze River, Qiantang River, and Pearl River (labeled in Fig. 1) whose $S_{\mathrm{P}}$ values less than 2 are recalculated with a modified form of the Hill et al. (1986) formula based on the in situ conductivity, temperature, and pressure. Then Eq. (3) is used to get $S_{\mathrm{R}}$.

Based on our observations (Fig. 1), the Reference Salinity $S_{\mathrm{R}}$ of Chinese offshore seawater diluted by low-salinity river runoff ranges from 0.01 to $34.66 \mathrm{~g} \mathrm{~kg}^{-1}$. The extreme minimum $S_{\mathrm{R}}$ of $0.01 \mathrm{~g} \mathrm{~kg}^{-1}$ appears in the south branch of Yangtze River in the summer of 2006, and the maximum of $34.66 \mathrm{~g} \mathrm{~kg}^{-1}$ appears in the path of the Kuroshio Current (Fig. 2). Low salinities are also seen in the Pearl River estuary and to a lesser degree in shallow areas of the southern Yellow Sea, as well as near a few other river mouths. 


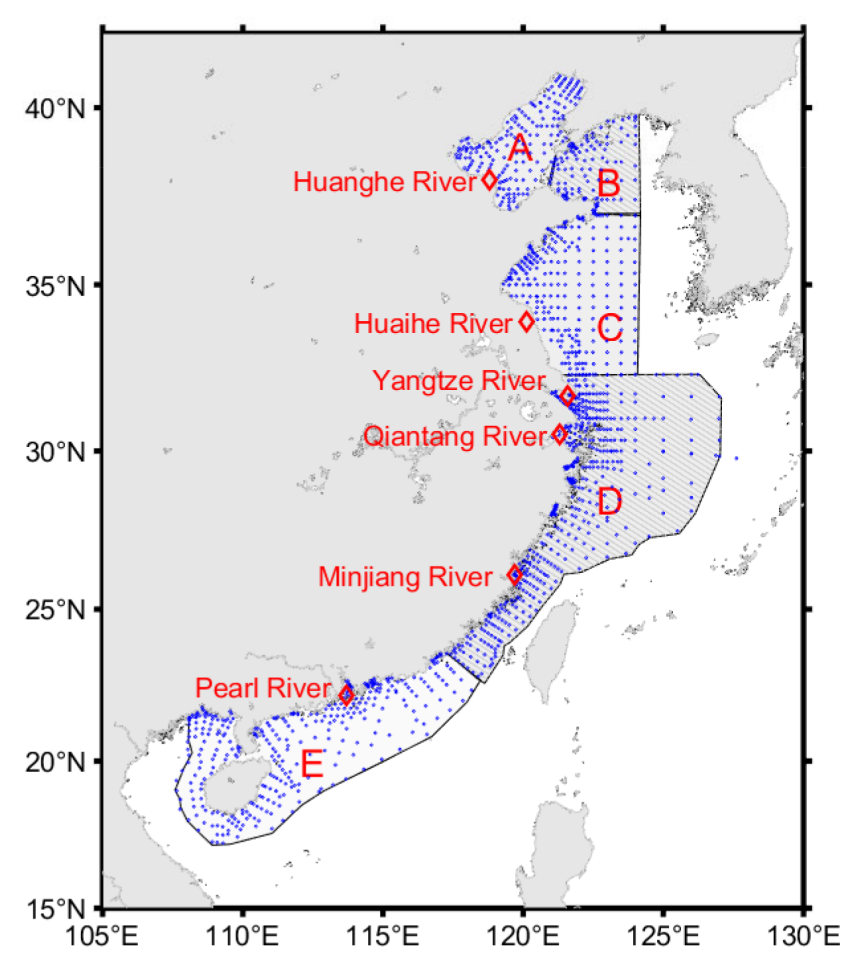

Figure 1. The geographical distribution map of sampling stations. The blue dots are the observation stations of the Marine Integrated Investigation and Evaluation Project of the China Sea. "A" is the Bohai Sea, " $B$ " is the northern Yellow Sea, "C" is the southern Yellow Sea, "D" is the East China Sea, and "E" is the South China Sea.

\subsection{Absolute Salinity Anomaly $\delta S_{\mathrm{A}}$ of Chinese offshore waters}

Using Eq. (6), the estimated $\delta S_{\mathrm{A}}$ of Chinese offshore waters ranges from -0.05 to $0.28 \mathrm{~g} \mathrm{~kg}^{-1}$ (Fig. 3). The largest Absolute Salinity Anomalies are 1 order higher than those of the open ocean. As much as $90 \%$ of the calculated $\delta S_{\mathrm{A}}$ arises from the $\Delta[\mathrm{NTA}]$ term in Eq. (6), so that areas with high $\delta S_{\mathrm{A}}$ also have high $\Delta[\mathrm{NTA}]$ (Fig. 4). The largest $\delta S_{\mathrm{A}}$ values appear in the Yangtze River estuary, Hangzhou Bay, Laizhou Bay, Bohai Bay, North Jiangsu Shoal, and the Pearl River estuary. Hangzhou Bay, which is adjacent to the Yangtze River estuary, has continuously transported water from the Yangtze River estuary due to its current and tidal characteristics (Yuan, 2009) and has almost the same water composition as the Yangtze River estuary. Thus, in this paper, the waters in the Yangtze River estuary and Hangzhou Bay are analyzed as a single water mass. The $\delta S_{\mathrm{A}}$ values in the above coastal regions, which are often in excess of $0.05 \mathrm{~g} \mathrm{~kg}^{-1}$, are given in Table 1.

The maximum $\delta S_{\mathrm{A}}$ of $0.28 \mathrm{~g} \mathrm{~kg}^{-1}$ appears at the sea surface of the Yangtze River estuary and in Hangzhou Bay in summer. As China's largest runoff into the sea, the Yangtze River is rich in nutrients from land. At its entrance to the sea, the silicate concentration exceeds $100 \mu \mathrm{mol} \mathrm{kg}-1$, $\Delta[\mathrm{NTA}]$ is larger than $1 \mathrm{mmol} \mathrm{kg}^{-1}$, and the $\delta S_{\mathrm{A}}$ is greater than $0.1 \mathrm{~g} \mathrm{~kg}^{-1}$ all year round, but these nutrient concentrations decrease rapidly away from the entrance. $\Delta[\mathrm{NTA}]$ is the primary contributor to $\delta S_{\mathrm{A}}$. The surface coverage of the $0.05 \mathrm{~g} \mathrm{~kg}^{-1}$ isocline varies with seasons and depths and reaches a maximum in summer but with little variation in other seasons. In this region, $54 \%$ and $26 \%$ of negative $\delta S_{\mathrm{A}}$ appear in spring and winter, respectively, which also mainly arises from $\Delta[\mathrm{NTA}]$.

In the northern North Jiangsu Shoal, the maximum $\delta S_{\mathrm{A}}$ of $0.23 \mathrm{~g} \mathrm{~kg}^{-1}$ appears in the bottom layer in winter. Centered at $33.4^{\circ} \mathrm{N}$ and $121^{\circ} \mathrm{E}$, many points have a $\delta S_{\mathrm{A}}$ greater than $0.05 \mathrm{~g} \mathrm{~kg}^{-1}$ all year round, which gradually decreases from the coast to the offshore. The $\delta S_{\mathrm{A}}$ of the bottom layer is higher than that of the surface layer in a dry season (spring and winter) but smaller in a flood (summer and autumn) season, in which more terrestrial input is brought by Huai River system.

The largest $\delta S_{\mathrm{A}}$ of $0.20 \mathrm{~g} \mathrm{~kg}^{-1}$ in the Bohai Sea appears at the bottom of Laizhou Bay in winter, and seasonal characteristics are basically the same as the North Jiangsu Shoal, although in summer more terrestrial material is input by the Yellow River. As the Bohai Sea is a semi-enclosed shallow sea with lower exchange with the open ocean, the $\delta S_{\mathrm{A}}$ in the whole Bohai Sea is always larger than $0.02 \mathrm{~g} \mathrm{~kg}^{-1}$ and the $\delta S_{\mathrm{A}}$ difference between the bottom and the surface within the same season is not as significant as its seasonal variation in the area.

A $\delta S_{\mathrm{A}}$ of greater than $0.05 \mathrm{~g} \mathrm{~kg}^{-1}$ also occurs at the mouth of the Pearl River and Min River in summer, but values are less than $0.02 \mathrm{~g} \mathrm{~kg}^{-1}$ in other seasons. However, these values are seen within the estuary with very little presence on the shelf. In the remaining areas, the magnitude of $\delta S_{\mathrm{A}}$ is below $0.005 \mathrm{~g} \mathrm{~kg}^{-1}$, which is about the same as the magnitude of the statistical uncertainty of the Absolute Salinity Anomaly in the open ocean and so is essentially zero.

Although we have used Eq. (6), which is meant for seawater of relatively high salinity, to estimate the Absolute Salinity Anomaly near river mouths where the salinity is far smaller, a more complex calculation of the $\delta S_{\mathrm{A}}$, based on a full chemical analysis of river water composition, was plotted for some of these rivers (the Yangtze, the Pearl and Min rivers) in Pawlowicz (2015). The values calculated in that work are consistent with those found here (Table 2).

\subsection{Parameterization of the Absolute Salinity of the China offshore waters}

Although the Absolute Salinity Anomalies within rivers are always non-zero, the Absolute Salinity Anomaly is significantly non-zero in only four areas along the Chinese coast and river mouths (hatched areas in Fig. 3). They are occupied by different coastal water masses (Xiong, 2012), and the 

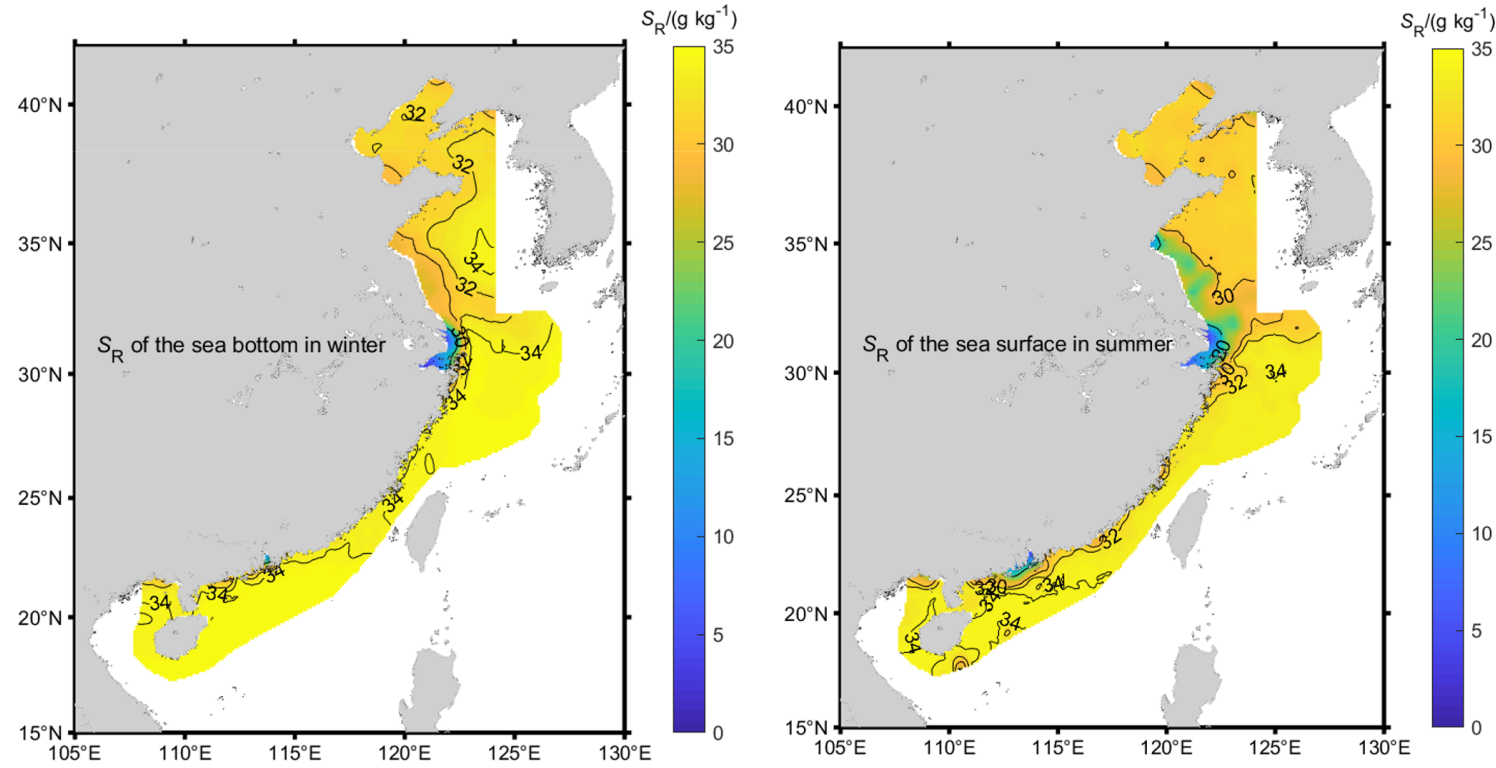

Figure 2. $S_{\mathrm{R}}$ isoclines of China offshore seawater.
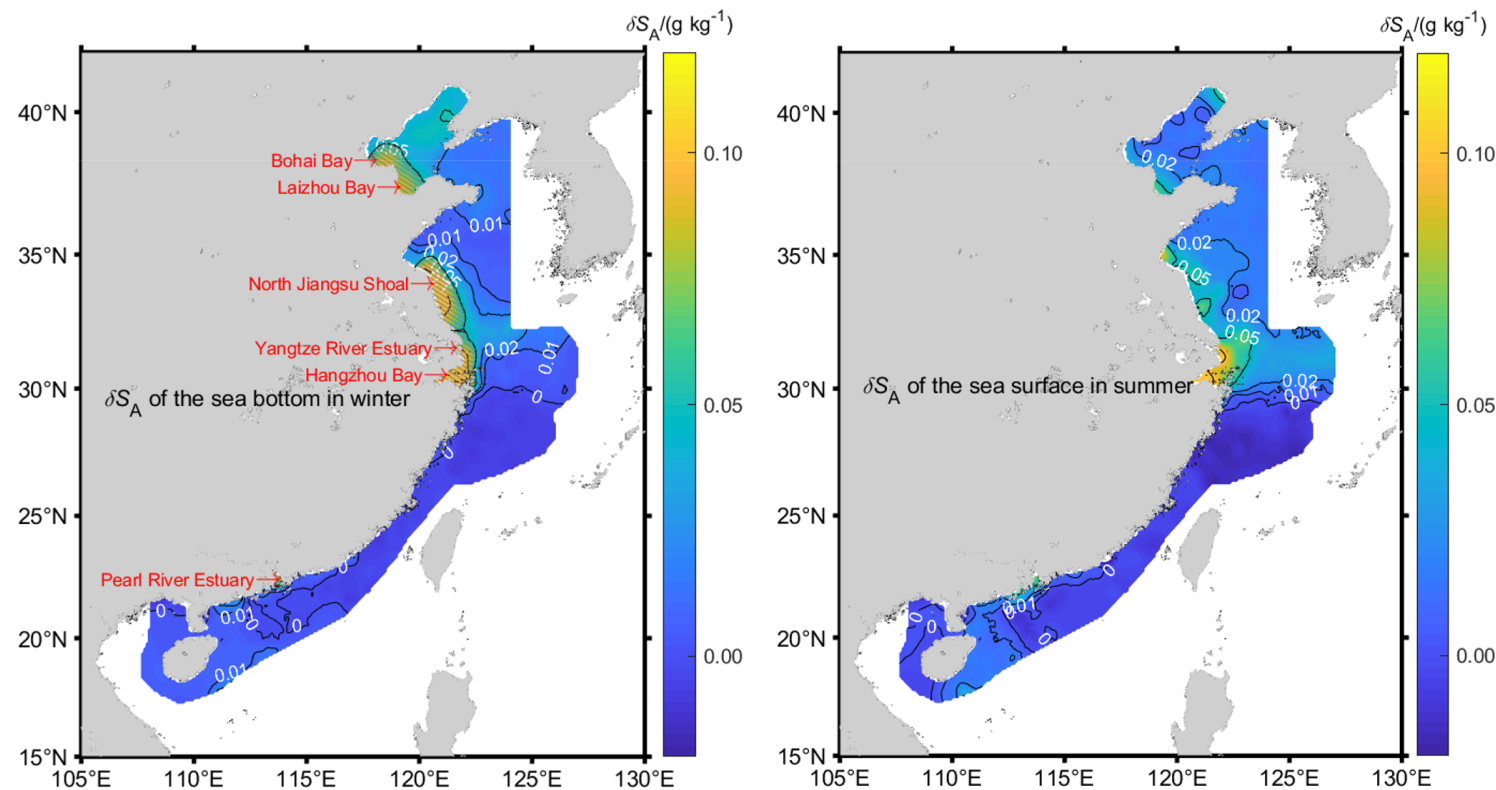

Figure 3. $\delta S_{\mathrm{A}}$ isoclines of Chinese offshore seawater. Hatched areas in the left figure represent the areas where $\delta S_{\mathrm{A}}$ is more than $0.05 \mathrm{~g} \mathrm{~kg}-1$.

Absolute Salinities Anomalies in each can be parameterized separately.

China offshore seawater is a mixture of the Kuroshio water originating from the North Equatorial Current and the runoff into the sea. The Absolute Salinity Anomaly in Pacific surface waters in any case is generally small; it is the deeper waters that have (relatively) large Absolute Salinity Anomalies arising from remineralization in the subsurface branch of the ocean's overturning circulation. In this paper, we ignore the relative composition difference between the Kuroshio and SSW for now. Following Feistel et al. (2010b), these four water masses are regarded as the mixture of Standard Seawater that has standard-ocean salinity, with the local coastal water which contains unknown amounts of unknown solute. The related regression lines of the four water masses between Absolute Salinity Anomaly and the Reference Salinity can be computed from the samples with salinity $S_{\mathrm{R}}>2 \mathrm{~g} \mathrm{~kg}^{-1}$, in which the seawater endpoints are chosen to be SSW with 

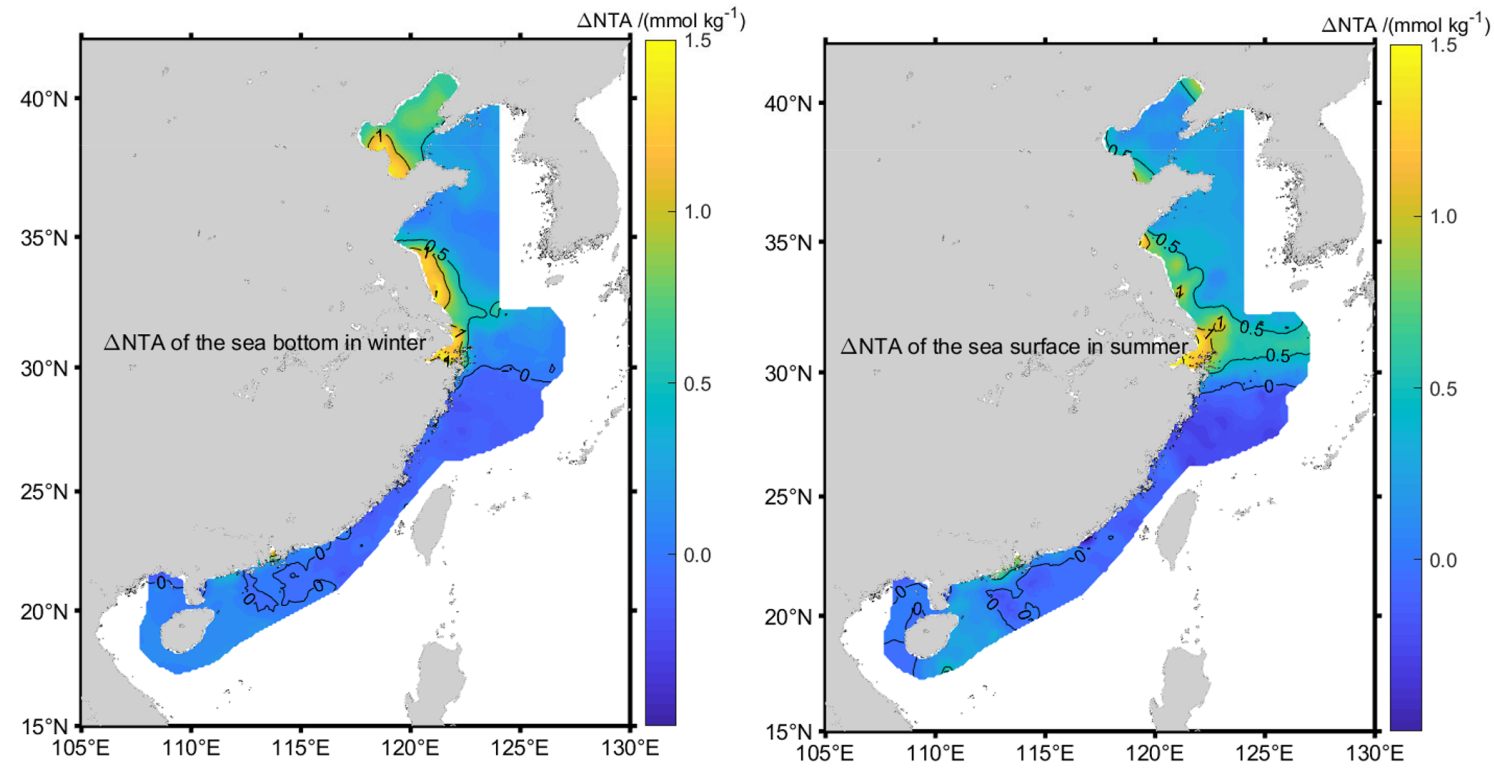

Figure 4. $\Delta[\mathrm{NTA}]$ isoclines of China offshore seawater.

Table 1. $\delta S_{\mathrm{A}}$ in different coastal regions hatched in Fig. 3. Units are milligrams per kilogram.

\begin{tabular}{lrrr}
\hline Region & Min & Max & Mean \pm SD \\
\hline Laizhou Bay and Bohai Bay & 0 & 132 & $54 \pm 23$ \\
North Jiangsu Shoal & 0 & 228 & $46 \pm 32$ \\
Yangtze River estuary and Hangzhou Bay & -50 & 279 & $86 \pm 63$ \\
Pearl River estuary & 0 & 125 & $52 \pm 32$ \\
\hline
\end{tabular}

a $\delta S_{\mathrm{A}}$ of zero, as shown in Eq. (11) and Fig. 5.

$$
\begin{gathered}
S_{\mathrm{A}}-S_{\mathrm{R}}=\left[\begin{array}{c}
412 \\
236 \\
150 \\
107
\end{array}\right] /\left(\mathrm{mgkg}^{-1}\right) \cdot\left(1-\frac{S_{\mathrm{R}}}{S_{\mathrm{SO}}}\right) \\
{\left[\begin{array}{c}
\text { Laizhou Bay and Bohai Bay } \\
\text { North Jiangsu Shoal } \\
\text { Yangtze River estuary and Hangzhou Bay } \\
\text { Pearl River estuary }
\end{array}\right]}
\end{gathered}
$$

The linear correlation between Absolute Salinity Anomaly and $S_{\mathrm{R}}$ in the Pearl River estuary is the strongest among the four regions, which shows that the mixture between the coastal seawater and that of the open ocean is relatively conservative. There are many measurements over all salinities for the Yangtze River water. The strong scatter visible in Fig. 5 at low salinities is likely due to the rich (and highly variable) nutrient loading brought by Yangtze River draining from land.

The regressions for the two northernmost areas are less precise, as the oceanographic sampling pattern does not enter into the rivers and measured salinities are larger than $25 \mathrm{~g} \mathrm{~kg}^{-1}$. The fitted curves are somewhat steeper. Note that

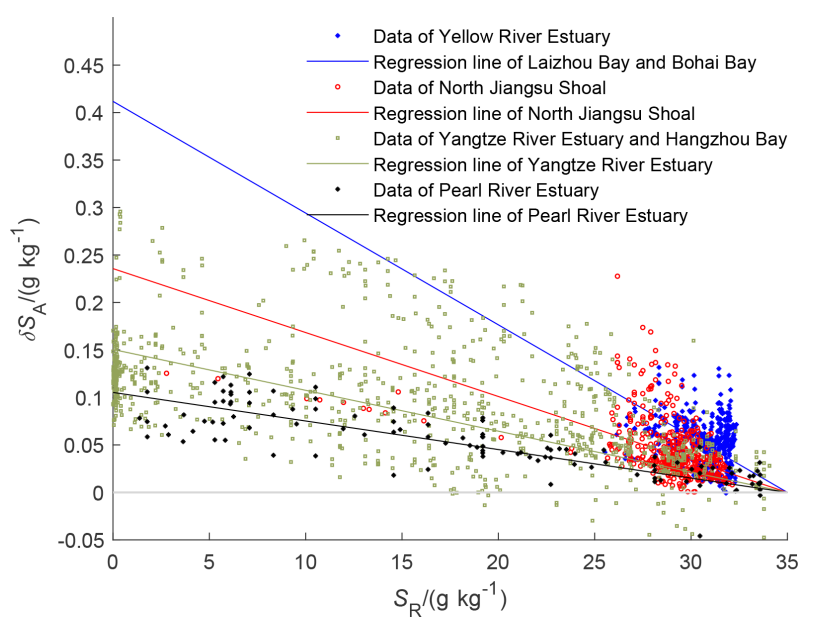

Figure 5. The Absolute Salinity Anomaly of the four regions of China offshore waters as a function of their Reference Salinity.

Pawlowicz (2015) also finds that Absolute Salinity Anomalies in the Yellow River of about $0.2 \mathrm{~g} \mathrm{~kg}^{-1}$ are also higher than in the other rivers (Table 2), although not as high as our fits in Fig. 5 suggest. The fit for the North Jiangsu Shoal region is heavily influenced by many high values when salin- 
Table 2. $\delta S_{\mathrm{A}}$ in some rivers as estimated in this paper, compared with values estimated using a more complete theory in Pawlowicz (2015). Units are milligrams per kilogram.

\begin{tabular}{lrr}
\hline Rivers & Mean \pm SD (our data) & Values from Pawlowicz (2015) \\
\hline Yellow River & - & $200-239$ \\
Yangtze River & $90 \pm 23$ & $105 \sim 116$ \\
Min River & $26 \pm 15$ & 30 \\
Pearl River & $80 \pm 26$ & $95 \sim 96$ \\
\hline
\end{tabular}

ities are between 20 and $25 \mathrm{~g} \mathrm{~kg}^{-1}$ and lies somewhat above a smaller number of values spread over lower salinities.

It can be seen from Fig. 5 that the relative composition anomalies decrease from north to south. The exchange of coastal waters with the open-ocean waters increases gradually from the northernmost (and somewhat enclosed) Bohai Sea estuary to the southernmost Pearl River area, which is open to the South China Sea.

\subsection{Relative composition anomaly of China offshore seawater}

In Eq. (6), the coefficients are determined by fitting to the results of more complete calculations that assume changes to $\mathrm{Ca}^{2+}$ to maintain a charge balance according to Eq. (7). We cannot directly check the accuracy of this assumption. However, $\mathrm{Ca}^{2+}$ was directly measured from samples in 13 cruises from April 2011 to February 2012 (Qi, 2013). Although these measurements do not occur at the same time as our larger dataset, we can group these measurements in the same regions (labeled in Fig. 1) in which we find large Absolute Salinity Anomalies. Then, we find that the $\Delta \mathrm{N}\left[\mathrm{Ca}^{2+}\right], \Delta\left[\mathrm{NO}_{3}^{-}\right]$, and $\Delta[\mathrm{NTA}]$ (first column) values from our dataset (Table 3) are approximately consistent with Eq. (7).

The other nutrient of phosphate is not considered in the calculation, for its concentrations range from 0 to $0.01 \mathrm{mmol} \mathrm{kg}^{-1}$ in the existing observation, which is much smaller than those items in Eq. (7) above, and its effect is negligible. In this case, $\Delta\left[\mathrm{NO}_{3}^{-}\right]$is mostly negligible and $\Delta \mathrm{N}\left[\mathrm{Ca}^{2+}\right]$ is about $43 \% \sim 58 \%$ of $\Delta[\mathrm{NTA}]$, in the Bohai Sear, southern Yellow Sea, East China Sea, and the Yangtze River.

The importation of $\mathrm{Ca}^{2+}$ and the carbon system suggest that the major source of Absolute Salinity Anomalies in shelf areas is the high $\mathrm{CaCO}_{3}$ content of rivers. This is consistent with Absolute Salinity Anomalies in the Baltic Sea, which were found to be mostly related to the calcium carbonate input from rivers (Feistel et al., 2010a). These rivers would be the Yangtze, Yellow River, and Huai rivers. The importation fluxes of $\mathrm{Ca}^{2+}$ into the sea from the Yellow River and the Yangtze River are $3.6 \times 10^{10}$ and $6.5 \times 10^{11} \mathrm{~mol} \mathrm{yr}^{-1}$, respectively, in 2011 (Qi, 2013). In addition, there may be re-dissolution of sediments in the Yellow River estuary and North Jiangsu Shoal. Due to the accumulation of materi- als entering the sea from the old Yellow River and the ancient Yangtze River, the $\mathrm{CaCO}_{3}$ concentration of surface sediments on the seafloor of the North Jiangsu Shoal ranges from $2.8 \%$ to $10.5 \%$ (Qin et al., 1989; Yang and Youn, 2007). The $\triangle$ NDIC of the southern Yellow Sea near China has always been high; even when strong biological activity in spring reduces the surface $\Delta[\mathrm{NTA}]$, the sediment of particulate inorganic carbon will resuspend and maintain the high level of dissolved $\mathrm{CaCO}_{3}$ of seawater through the solid-liquid balance (Hong, 2012; Zhang et al., 1995).

\subsection{Contrast to the $\delta S_{\mathrm{A}}$ calculated by GSW}

Using the GSW function library and the corresponding climatological silicate and Practical Salinity data, the calculated $\delta S_{\mathrm{A}}$ of China offshore waters ranges from 0 to $0.002 \mathrm{~g} \mathrm{~kg}^{-1}$. This is 2 orders of magnitude less than the values calculated in Sect. 3.2. The spatial distribution characteristics are also significantly different. These differences mainly come from the following aspects:

1. Instead of silicate, $\mathrm{CaCO}_{3}$ is most likely the main relative composition anomaly of China offshore seawater and the primary contributor to the $\delta S_{\mathrm{A}}$, where it is greater than $0.05 \mathrm{~g} \mathrm{~kg}^{-1}$.

2. High silicate concentrations (up to $100 \mu \mathrm{mol} \mathrm{kg}{ }^{-1}$ ) do appear in Chinese coastal seawaters from the effects of rivers (Fig. 6), but these do not appear in the global silicate climatology used for the GSW calculations. However, even if they did, in these places $\Delta[\mathrm{NTA}]$ is even larger, so that the effects of this coastal silicate on the Absolute Salinity Anomaly are small.

In the remaining areas, the silicate concentration is less than $20 \mu \mathrm{mol} \mathrm{kg}{ }^{-1}$, as shown in Fig. 6 at a $95 \%$ degree of confidence; the difference between the observation and the GSW climatological dataset is $[5.46,6.21] \mu \mathrm{mol} \mathrm{kg}^{-1}$, which does not change much with the seasons. It can be indicated that the GSW climatological dataset basically reflects the distribution characteristics of silicate in these areas.

\section{Conclusion and analysis}

The proposal and implementation of the concept of $S_{\mathrm{A}}$ in TEOS-10 are meant to accurately quantify the total mass of 
Table 3. The mean value of $\Delta[\mathrm{NTA}], \Delta\left[\mathrm{NO}_{3}^{-}\right], \Delta[\mathrm{NTA}]^{*}$, and $\Delta \mathrm{N}\left[\mathrm{Ca}^{2+}\right]^{*}$ are given in different areas (marked in Fig. 1). Values obtained from Qi (2013) are labeled with “*”. Units are micromole per kilogram.

\begin{tabular}{|c|c|c|c|c|}
\hline Region & $\Delta[\mathrm{NTA}]$ & $\Delta\left[\mathrm{NO}_{3}^{-}\right]$ & $\begin{array}{c}\Delta[\mathrm{NTA}]^{*} \\
(\mathrm{Qi}, 2013)\end{array}$ & $\begin{array}{r}\Delta \mathrm{N}\left[\mathrm{Ca}^{2+}\right]^{*} \\
(\mathrm{Qi}, 2013)\end{array}$ \\
\hline Bohai & $620 \pm 339$ & $13.6 \pm 11.3$ & - & $364 \pm 115$ \\
\hline Southern Yellow Sea & $318 \pm 330$ & $6.8 \pm 10.1$ & - & $136 \pm 46$ \\
\hline East China Sea & $170 \pm 540$ & $16.4 \pm 23.0$ & - & $90 \pm 54$ \\
\hline \multirow{3}{*}{ South branch of Yangtze River $\left(S_{\mathrm{P}}<1\right)$} & $1727 \pm 301$ in Feb and Apr & $112.06 \pm 18.84$ & 1845 & $981 \sim 1014$ \\
\hline & $1770 \pm 150$ in Jul & $101.45 \pm 4.67$ & $1696 \sim 1869$ & $925 \sim 936$ \\
\hline & $1977 \pm 304$ in Oct & $81.42 \pm 9.62$ & 1900 & 992 \\
\hline North branch of Yangtze River estuary $\left(8<S_{\mathrm{P}}<20\right)$ & & & $245 \sim 480$ & $132 \sim 250$ \\
\hline
\end{tabular}

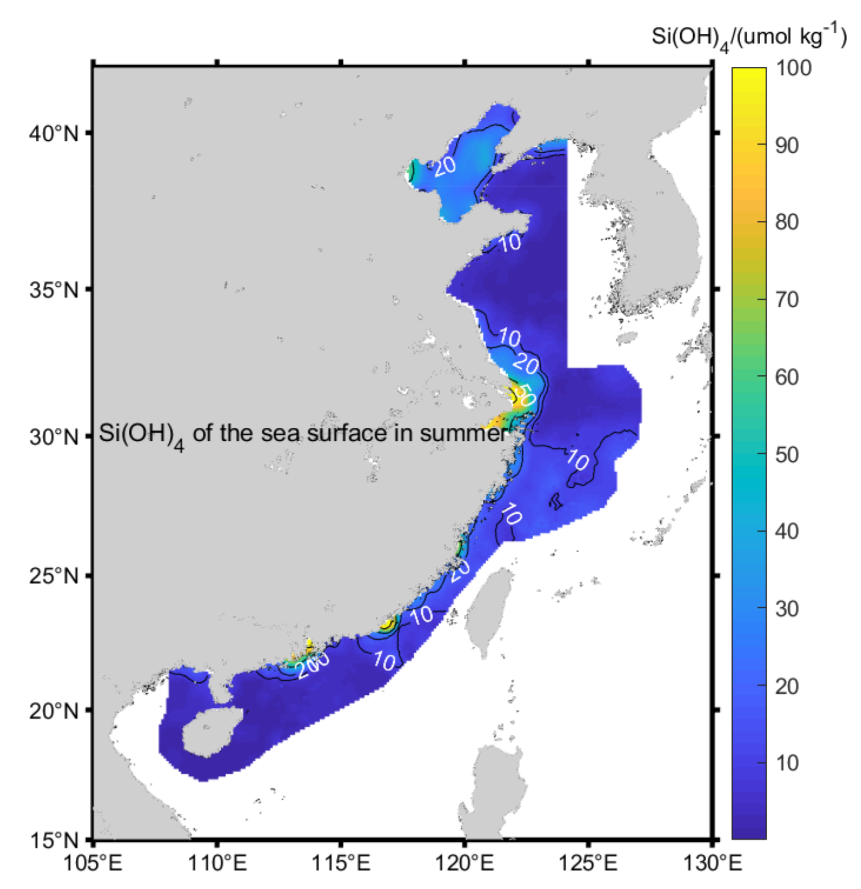

Figure 6. $\mathrm{S}_{i}(\mathrm{OH})_{4}$ isoclines of sea surface in summer.

inorganic substance dissolved in seawater, to ensure that the density and related quantities are accurately represented by the Gibbs function for seawater, and to correct errors caused by measuring the properties of seawater such as chloride and conductivity to get the salinity. In this paper, based on observations and calculations, the magnitude, distribution characteristics of Absolute Salinity in China offshore waters are described as follows:

1. The Absolute Salinity $S_{\mathrm{A}}$ ranges from 0.1 to $34.66 \mathrm{~g} \mathrm{~kg}^{-1}$, in which $S_{\mathrm{R}}$ ranges from 0.01 to $34.66 \mathrm{~g} \mathrm{~kg}^{-1}$, and the Absolute Salinity Anomaly $\delta S_{\mathrm{A}}$ ranges from -0.05 to $0.28 \mathrm{~g} \mathrm{~kg}^{-1}$; this is an order of magnitude larger than the largest values in the open ocean.
2. The largest $\delta S_{\mathrm{A}}$ values are located in four distinct regions: the Yangtze River mouth/Hangzhou Bay, the North Jiangsu Shoal, the Bohai Sea, and the Pearl River mouth, all of which are areas where the $\Delta[\mathrm{NTA}]$ is high.

3. Instead of silicate, $\mathrm{CaCO}_{3}$ is most likely the main composition anomaly relative to SSW and the primary contributor to the $\delta S_{\mathrm{A}}$ in the above four areas.

4. Under the combined effects of different water system dynamics, terrestrial input, marine biological activities, and re-dissolution of marine sediments, the $\delta S_{\mathrm{A}}$ values in China offshore waters' seasonal variations are obvious, and the maximum can be as high as $0.05 \mathrm{~g} \mathrm{~kg}^{-1}$; the difference between the surface layer and the bottom layer is also up to $0.1 \mathrm{~g} \mathrm{~kg}^{-1}$.

With the observations available, this paper only lists the magnitude and distribution characteristics of $\delta S_{\mathrm{A}}$ in China offshore waters from 2006 to 2007, although it is likely that similar features will occur in other years. At present, we have collated the long-term series of seawater composition data to continue the study on $\delta S_{\mathrm{A}}$ changes and get an empirical formula to calculate $\delta S_{\mathrm{A}}$.

The current research is only based on the existing seawater composition data, and the exact influence of other changes to composition is still not very clear. To verify these findings, a complete chemical analysis and/or direct measurements of seawater density would be useful in the estuaries of the Yangtze River, Qiantang River, Pearl River, Min River, and the semi-enclosed Bohai Sea.

Code availability. MATLAB-version of CO2SYS is available at https://github.com/jamesorr/CO2SYS-MATLAB (Lewis and Wallace, 2021).

Data availability. The research data used in this manuscript have not been publicly available yet because the investigators are still conducting relevant research based on these massive data. At present, the relevant atlas and research reports have been officially 
published and listed in the references list: (1) State Ocean Administration of China: China Offshore Atlas - Ocean Chemistry, ocean press, Beijing, 2016. (2) State Ocean Administration of China: China Offshore Atlas - Oceanography, ocean press, Beijing, 2016. (3) Xiong, X. J.: China Regional Oceanography and Marine Meteorology,Ocean Press, Beijing, 2012. (4) Ji, W. D.: China Offshore Ocean Chemistry, Ocean Press, Beijing, 2016.

Author contributions. FJ was responsible for method design and implementation, writing original drafts, verifying editorial opinions, and reviewing and editing. RP revised a few key theories in the draft, provided the model data to verify the result in the draft, and was involved in review and editing. XX was the project administrator and was involved in topic selection and review and editing.

Competing interests. The authors declare that they have no conflict of interest.

Acknowledgements. The authors express their gratitude to Guo Xianghui and Wang Haili from Xiamen University for providing useful suggestions for marine chemical data evaluation.

Financial support. This research has been supported by the National Natural Science Foundation of China (grant no. 41406024) and the National Key Research and Development Program of China (grant no. 2017YFA0604904).

Review statement. This paper was edited by Trevor McDougall and reviewed by Paul Barker and two anonymous referees.

\section{References}

Commission of Science and Technology of the People's Republic of China: Report of the National Comprehensive Marine Survey, Volume I, 1964.

Feistel, R., Marion, G. M., Pawlowicz, R., and Wright, D. G.: Thermophysical property anomalies of Baltic seawater, Ocean Sci., 6, 949-981, https://doi.org/10.5194/os-6-949-2010, 2010a.

Feistel, R., Weinreben, S., Wolf, H., Seitz, S., Spitzer, P., Adel, B., Nausch, G., Schneider, B., and Wright, D. G.: Density and Absolute Salinity of the Baltic Sea 2006-2009, Ocean Sci., 6, 3-24, https://doi.org/10.5194/os-6-3-2010, 2010b.

Gouretski, V. V. and Koltermann, K. P.: WOCE Global Hydrographic Climatology, Berichte des Bundesamtes fur Seeschifffahrt und Hydrographie, Tech. Rep., 35, 49, 2004.

Hill, K. D., Dauphinee, T. M., and Woods, D. J.: The extension of the Practical Salinity Scale 1978 to low salinities, IEEE J. Ocean. Eng., OE-11, 109-112, 1986.

Hong, H. S.: China Regional Oceanography - Chemical Oceanography, Ocean Press, Beijing, 2012.

IOC, SCOR, IAPSO: The International Thermodynamic Equation of Seawater - 2010: Calculation and Use of Thermody- namic Properties. Manual and Guides No. 56, Intergovernmental Oceanographic Commission, UNESCO (English), 2010.

Ji, W. D.: China Offshore - Ocean Chemistry, Ocean Press, Beijing, 2016.

Lewis, E. and Wallace, D. W. R.: Program developed for $\mathrm{CO}_{2}$ system calculations, ORNL/CDIAC-105, Oak Ridge National Laboratory, 1998.

Lewis, E. and Wallace, D. W. R.: Program Developed for $\mathrm{CO}_{2}$ System Calculations, Github [Dataset], available at: https://github. com/jamesorr/CO2SYS-MATLAB, last access: 8 June 2021.

Li, Y., Luo, Y., Kang, Y., Yu, T., Wang, A., and Zhang, C.: Chinese primary standard seawater: stability checks and comparisons with IAPSO Standard Seawater, Deep-Sea Res., 113, 101106, 2016.

Lv, C. L.: Analysis of decadal variability of salinity field and its influence to circulation in Bohai and northern Yellow Sea, The Master Degree Dissertation of China Ocean University, 2008.

McDougall, T. J. and Barker, P. M.: Getting started with TEOS-10 and the Gibbs Seawater (GSW) Oceanographic Toolbox, 28 pp., SCOR/IAPSO WG127, ISBN 978-0-646-55621-5, 2011.

McDougall, T. J., Jackett, D. R., Millero, F. J., Pawlowicz, R., and Barker, P. M.: A global algorithm for estimating Absolute Salinity, Ocean Sci., 8, 1123-1134, https://doi.org/10.5194/os-81123-2012, 2012.

Millero, F. J.: The conductivity-density-salinity-chlorinity relationships for estuarine waters, Limnol. Oceanogr., 29, 13171321, 1984.

Millero, F. J., Feistel, R., Wright, D. G., and McDougall, T. J.: The composition of Standard Seawater and the definition of the Reference-Composition Salinity Scale, Deep-Sea Res. Pt. I, 55, 50-72, 2008.

Pawlowicz, R.: Calculating the conductivity of natural waters, Limnol. Oceanogr.: Methods, 6, 489-501, 2008.

Pawlowicz, R.: A model for predicting changes in the electrical conductivity, practical salinity, and absolute salinity of seawater due to variations in relative chemical composition, Ocean Sci., 6, 361-378, https://doi.org/10.5194/os-6-361-2010, 2010.

Pawlowicz, R.: The Absolute Salinity of seawater diluted by river water, Deep-Sea Res. Pt. I, 101 71-79, 2015.

Pawlowicz, R., Wright, D. G., and Millero, F. J.: The effects of biogeochemical processes on oceanic conductivity/salinity/density relationships and the characterization of real seawater, Ocean Sci., 7, 363-387, https://doi.org/10.5194/os-7-363-2011, 2011.

Qi, D.: Dissolved calcium in the Yangtze River Estuary and China Offshore, The Master Degree Dissertation of Xiamen University, 2013.

Qin, Y. S., Zhao, Y. Y., and Chen L. R.: Huanghai Geology, Science Press, Beijing, 1989.

Song, W. P.: The analysis of the structure of T-S and the current characteristics in Bohai Sea during winter and summer, The Master Degree Dissertation of China Ocean University, 2009.

UNESCO: The Practical Salinity Scale 1978 and the International Equation of State of Seawater 1980, UNESCO Technical Papers in Marine Science, 36, 25 pp., 1981.

Yuan, J. Z.: Study on water exchange characteristics between Yangtze Estuary and Hangzhou Bay, The Third Yangtze River Forum Proceedings (in Chinese), 183-191, 2009. 
Woosley, R. J., Huang, F., and Millero, F. J.: Estimating absolute salinity $\left(S_{\mathrm{A}}\right)$ in the world's oceans using density and composition, Deep Sea Res. Pt. I, 93, 14-20, 2014.

Wright, D. G., Pawlowicz, R., McDougall, T. J., Feistel, R., and Marion, G. M.: Absolute Salinity, "Density Salinity" and the Reference-Composition Salinity Scale: present and future use in the seawater standard TEOS-10, Ocean Sci., 7, 1-26, https://doi.org/10.5194/os-7-1-2011, 2011.

Wu, D. X., Mu, L., Li, Q., Bao, X.W, and Wan, X. Q.: Characteristics of long-term change and its possible dominant factors in Bohai Sea, Progress in Nature Science, 14, 191-195, 2004a.
Wu, D. X., Wan, X.Q, Bao, X.W, Mu, L., and Lan, J.: Comparison of temperature-sallinity field and circulation Structure in the Summer between 1958 and 2000, Chinese Sci. Bull., 49, 287292, 2004b.

Xiong, X. J.: China Regional Oceanography and Marine Meteorology, Ocean Press, Beijing, 2012.

Xu, J. L.: The variation characters and formation mechanism of salinity in the Bohai Sea, The Master Degree Dissertation of China Ocean University, 2007.

Yang, S. Y. and Youn J. S.: Geochemical compositions and provenance discrimination of the central south Yellow Sea sediments, Mar. Geol., 243, 229-241, 2007.

Zhang, J., Huang, W. W., Létolle, R., and Jusserand, C.: Major element chemistry of the Huanghe River (Yellow River), Chinaweathering processes and chemical fluxes, J. Hydrol., 168, 173203, 1995. 